специалистов // Самарский научный вестник. 2016. № 2 (15). С. 189-194.

6. Носков С.А. Дидактические возможности визуализации образовательной информации // Вестник Самарского государственного технического университета. Серия: Психолого-педагогические науки. 2015. № 2 (26). С. 144-149.

7. Плеханова Т.М. Реальное практико-ориентированное учебное проектирование как фактор развития и формирования у студентов профессиональной компетентности // Вестник самарского государственного технического университета. Серия: Психолого-педагогические науки. 2015. № 2 (26). С. 138-145.

8. Аниськин В.Н., Богословский В.И., Жукова Т.А., Рябинова Е.Н. Перспективы развития системы мультикультурного образования // Вестник Самарского государственного технического университета. Серия «Психолого-педагогические науки». 2015. № 1 (25). C. 9-17.

9. Тимощук Н.А. Метапредметность в образовании XXI века // Материалы Всероссийской научнопрактической конференции «Человеческий потенциал в 21 веке: образование и культура, патриотизм и традиции казачества, здоровый социум и инновационная экономика». Димитровград, 2016.

10. Носков С.А. Имитационное моделирование содержания и форм профессиональной деятельности специалиста по связям с общественностью // Акту- альные проблемы развития высшего и среднего образования на современном этапе: Всерос. науч.-практ. конф. Самара: Издательство Самарского научного центра РАН, 2012. С. 244-247.

11. Рябинова Е.Н., Марченкова Л.А. К вопросу об актуальности формирования вербальных компетенций студентов технических вузов // Вестник Самарского государственного технического университета. Серия «Психолого-педагогические науки». 2015. № 2(26). С. 163-170.

12. Игнатьева Е.Ю. Метапроект как технология педагогического управления учебной деятельностью студентов в современном вузе // Вестник Вятского государственного гуманитарного университета. 2011. № 4-3. С. 41-45.

13. Кустов Ю.А. Формирование общепрофессиональных компетенций студентов в воспитательном процессе вуза (аксиологический подход): монография. Тольятти: Кассандра, 2015. 168 с.

14. Колесина К.Ю. Метапроектное обучение: теория и технологии реализации в учебном процессе. Ростов-на-Дону, 2009. 412 с.

15. Тимощук Н.А. Формирование метапредметной компетентности у студентов технического университета // Вестник Самарского государственного технического университета. Серия «Психолого-педагогические науки». 2015. № 3 (27). С. 233-241.

\title{
IMPLEMENTATION OF SYNERGETIC APPROACH IN EDUCATION BASED ON THE META-PROJECT METHOD
}

(C) 2016

\author{
S.A. Noskov, lecturer of the Chair of Psychology and Pedagogics \\ Samara State Technical University, Samara (Russia)
}

\begin{abstract}
The paper analyzes the approaches to understanding the educational synergy and concludes that the key moment in the realization of the synergistic approach in education is the integration of a variety of knowledge-based interdisciplinary connections. Analysis of Russian universities training plans for different areas of training showed that they differ in a small number of integrated courses, and therefore concluded that it is necessary to implement alternative methods of interdisciplinary connections formation in the educational process, taking into account the multidimensional professional and educational environment. The author considers the possibility of implementing a synergetic approach to the meta-project-based method. The educational meta-project as a special form of independent activity of students is defined; specifics and peculiarities of meta-projects implementation and stages of cognitive meta-project technology are described. Meta-projects implementation may include a variety of forms and methods of training from different educational technologies, but cause the specific challenges facing the lecturer which are presented in the content of the paper. The results of experimental testing confirmed the positive impact of the meta-project method application on the formation of interdisciplinary relationships and integral vision of the future professional work of students, as well as on the development of learners' basic skills: thinking, understanding, communication, reflection and action.

Keywords: synergetic approach to education; educational synergy; project activities; educational technology; metaproject; meta-subject training; meta-cognitive project-based technology; professional competence; meta-subject competence; interdisciplinarity.
\end{abstract}

\section{УЧЕБНО-МЕТОДИЧЕСКОЕ ПОСОБИЕ КАК СРЕДСТВО ФОРМИРОВАНИЯ МЕЖДИСЦИПЛИНАРНЫХ СВЯЗЕЙ В ПРОЦЕССЕ ПОДГОТОВКИ БАКАЛАВРОВ}

(C) 2016

Т.М. Плеханова, старший преподаватель кафедры психологии и педагогики Самарский государственный технический университет, Самара (Россия)

\footnotetext{
Аннотащия. В данной статье рассматриваются теоретические аспекты и актуальность междисциплинарного подхода в педагогическом процессе. В качестве средства формирования междисциплинарных связей в процес- 
се подготовки бакалавров, обучающихся по направлению 42.03.01 Реклама и связи с общественностью предлагается разработанное на базе кафедры психологии и педагогики СамГТУ междисциплинарное учебнометодическое пособие по связям с общественностью. Учебно-методическое пособие является частью учебнометодического комплекса по дисциплинам «Теория и практика связей с общественностью», «Теория и практика массовой информации», «Основы теории коммуникации» и предназначено для использования в рамках проведения практических занятий. Междисциплинарный потенциал учебно-методического пособия заключается в том, что содержание и дидактические единицы различных дисциплин дополняют друг друга, формируют единое целостное восприятие изучаемой темы; с точки зрения формируемых компетенций студенты приобретают широкий набор владений, умений и навыков, студенты более полно воспринимают преемственность и последовательность между планируемыми результатами освоения дисциплин. Внедрение пособия в процесс обучения бакалавров 3 курса, обучающихся по направлению «Реклама и связи с общественностью» позволит повысить уровень подготовки студентов за счет аккумуляции знаний, умений, владений из разных дисциплин для решения профессиональной задачи.

Ключевые слова: междисциплинарность; междисциплинарное обучение; учебно-методическое пособие; педагогический процесс; бакалавриат; студенты; дисциплины; компетенции; владения; умения; навыки; Самарский государственный технический университет; реклама; связи с общественностью; коммуникация.

Реализация программы подготовки бакалавров предполагает не только обновление учебных курсов, программ, рабочих и индивидуальных планов, учебно-методической литературы, программно-информационного обеспечения, но и создание абсолютно новых учебников и учебных пособий, отвечающих требованиям Федерального государственного образовательного стандарта. Образовательные инновации должны проявиться не только в компетентностном подходе, но и в расширении спектра педагогических технологий, в выборе адекватной стратегии обучения [1, с. 5; 2].

На современном этапе развития общества, в условиях усложнения производственных отношений, его технической и социальной инфраструктуры решающим оказывается изменение отношения образовательных структур к подготовке специалистов в любой области. Это существенным образом зависит от организации целостного педагогического процесса, который заключается в создании новых организационных приемов, объединении научных направлений, инновационной деятельности [3; 4].

В современных условиях динамично меняющейся профессиональной среды, характеризующейся высоким уровнем конкуренции, у студентов, как у будущих субъектов профессиональной деятельности, необходимо сформировать компетенции, способствующие своевременному реагированию не только на изменения среды, но и на изменения потребностей и интересов целевых групп общественности $[5 ; 6 ; 7 ;]$. Формирование актуальных компетенций возможно в условиях междисциплинарного подхода [8;9].

Изучением вопросов междисциплинарности в образовании занимаются многие исследователи [10]. Среди зарубежных авторов стоит отметить работы Т. Аусбегр, Дж. Томпсон, Дж. Ганна, изучающих исторические предпосылки междисциплинарности. Интересы Х. Якобса, Р. Эверетта, Н. Моти, Д. Дэвида и Дж. Джери сосредоточены в области педагогической междисциплинарности. Ряд ученых, среди которых Р. Кёниг, Г. Бергер, Р. Акоф, объектом изучения выбрали для себя междисциплинарные исследования [11]. Среди отечественных исследователей вопросов междисциплинарности в педагогическом процессе стоит отметить Г.Л. Тульчинского, Е.А. Бушковской, Е.И. Снопковой $[12 ; 13]$.

Стоит, однако, отметить, что на сегодняшний день вопрос междисциплинарности в педагогике доста- точно обширен, что обуславливает необходимость проведения дальнейших исследований.

Целью исследования явилось изучение особенностей формирования междисциплинарных связей в процессе подготовки бакалавров на примере разработанного на базе кафедры психологии и педагогики СамГТУ междисциплинарного учебно-методического пособия по связям с общественностью.

Междисциплинарность, по мнению Х. Якобса это вид знания и подход к курсу обучения, которые сознательно включают методологию и язык более чем одной дисциплины для рассмотрения центральной темы, проблемы, события. В отличие от традиционного взгляда на сумму знаний отдельной дисциплины, междисциплинарность не делает акцент на ограничения знания, а сосредотачивается на связях и взаимоотношениях между разными дисциплинами, изучающими свой предмет [11].

Согласно Е.А. Бушковской, основой междисциплинарного обучения является тематическая междисциплинарная интеграция. Тематическая междисциплинарная интеграция - способ организации содержания обучения, в основе которого лежит интеграция объектов изучения, тем, проблем из разных областей знаний посредством их содержательного связывания с общими идеями междисциплинарного характера, которые раскрывают смысл глобальной темы [14].

Междисциплинарный подход в педагогике определяется Е.И. Снопковой как круг проблем, решаемых внутри педагогической науки с целью преодоления системы методологических ограничений, мешающих ее развитию в соответствии с динамикой науки в истории развития человеческого общества и культуры, изменчивостью норм, стратегий, критериев, программ исследовательской деятельности [15].

Э.М. Мирским выделено 3 вида проблем, решаемых в процессе междисциплинарного обучения:

- методологическая (формирование объекта изучения в разных предметных проекциях);

- организационная (создание сети коммуникаций представителей разных научных дисциплин);

- информационная (передача прикладных результатов обучения в практику принятия решений и их воплощения, передача научных результатов для экспертизы в системы дисциплинарного знания) [15].

Рассматриваемое в качестве средства формирования междисциплинарных связей междисциплинарное 
учебно-методическое пособие является частью учебно-методического комплекса по дисциплинам «Теория и практика связей с общественностью», «Теория и практика массовой информации», «Основы теории коммуникации» и предназначено для использования в рамках проведения практических занятий для подготовки бакалавров по направлению 42.03.01 Реклама и связи с общественностью.

В соответствии с действующим ГОСТ 7.60-2003 «Издания. Основные виды. Термины и определения» учебно-методическое пособие - учебное издание, содержащее систематизированные материалы по методике самостоятельного изучения учебной дисциплины, тематику и методику различных практических форм закрепления знаний (контрольных, курсовых, дипломных работ), изложенных в форме, удобной для изучения и усвоения [16, с. 7].

Как и любой тип учебной литературы учебнометодическое пособие имеет свое четко определенное целевое назначение. Целевое назначение учебнометодического пособия отражает функцию, которую выполняет данный тип изданий. Так, основной функцией учебно-методического пособия является обеспечение самостоятельной работы студентов по овладению знаниями и их закреплению $[17 ; 18]$.

Целью рассматриваемого междисциплинарного учебно-методического пособия по связям с общественностью является формирование у бакалавров общепрофессиональных и профессиональных компетенций, которые необходимы для реализации организационно-управленческой деятельности.

Задачи междисциплинарного учебно-методического пособия по связям с общественностью:

- формирование у бакалавров способности осуществлять под контролем профессиональные функции в области рекламы и связей с общественностью в различных структурах;

- формирование у бакалавров знаний и навыков работы в отделах рекламы/связей с общественность;

- формирование у бакалавров умения планировать и готовить под контролем коммуникационные кампании и мероприятия;

- формирование у бакалавров способности принимать участие в управлении и организации работы рекламных служб и служб по связям с общественностью фирмы и организации, осуществлять оперативное планирование и оперативный контроль рекламной работы, деятельности по связям с общественностью, проводить мероприятия по повышению имиджа организации, продвижению товаров и услуг фирмы на рынок, оценивать эффективность рекламной деятельности и связей с общественностью.

Междисциплинарность данного учебно-методического пособия реализуется на двух уровнях:

1. Уровень дисциплин. Рассматриваемые дисциплины имеют различные объекты изучения и содержание. Однако в своей структуре все три дисциплины имеют общую тематику, позволяющую объединить их в рамках единого учебно-методического пособия коммуникационный процесс.

2. Уровень компетенций. Каждая из рассматриваемых дисциплин призвана формировать различный набор компетенций. В процессе обучения с использованием предлагаемого учебно-методического пособия в рамках каждой дисциплины студенты могут осваивать более широкий набор общепрофессиональных и профессиональных компетенций.

В связи с этим в процессе изучения отдельной дисциплины может быть достигнуто полное либо частичное формирование у студентов дополнительных компетенций, присущих сопутствующим дисциплинам.

Формирование общепрофессиональных и профессиональных компетенций у будущих выпускников обеспечивает их дальнейшее вхождение в профессиональную среду [19; 20].

Рассмотрим интерпретацию содержания учебнометодического пособия в рамках каждой из рассматриваемых дисциплин в соответствии с рабочими программами дисциплин на примере Темы 1 «Возникновение и развитие PR. Исторический аспект» пособия (табл. 1).

Таблица 1 - Интерпретация содержания учебнометодического пособия в рамках каждой из рассматриваемых дисциплин

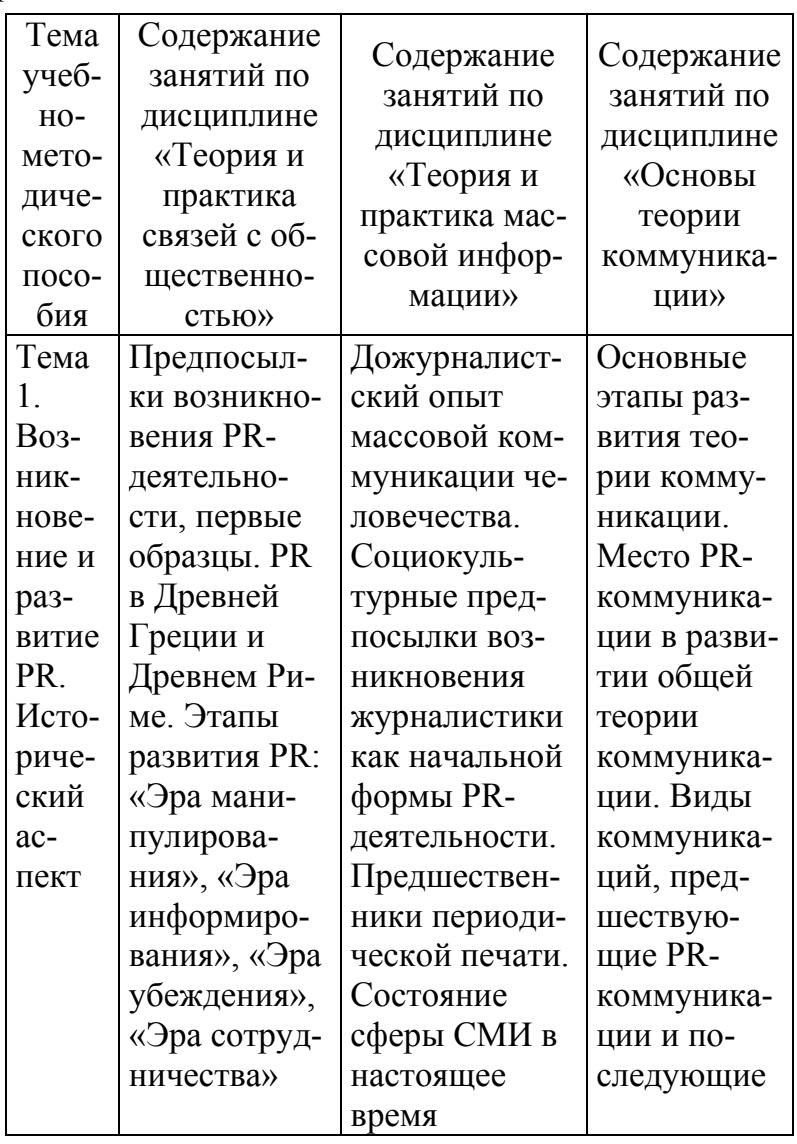

Как видно из таблицы 1, общую тему каждая дисциплина наполняет собственным содержанием, дидактические единицы дополняют друг друга, формируют единое целостное восприятие изучаемой темы.

Рассмотрим также междисциплинарность учебнометодического пособия с точки зрения формируемых компетенций.

Рассматриваемые дисциплины формируют общую компетенцию ОПК-4: Умение планировать и готовить под контролем коммуникационные кампании и мероприятия. Междисциплинарность в данном случае заключается в том, что общую компетенцию каждая дисциплина наполняет индивидуальными плани- 
руемыми результатами обучения: владениями, знаниями и умениями, приобретаемыми студентами в процессе освоения дисциплины. В данном случае, осваивая одну компетенцию, студенты приобретают широкий набор владений, умений и навыков. Исключается дублирование планируемых результатов обучения, возникает взаимосвязь между читаемыми дисциплинами, студенты более полно воспринимают преемственность и последовательность владений, умений и знаний по рассматриваемым дисциплинам.

В итоге отметим, что в настоящий момент рассматриваемое учебно-методическое пособие по связям с общественностью:

- рассмотрено и одобрено на заседании кафедры психологии и педагогики СамГТУ;

- рассмотрено и одобрено на заседании методического совета факультета гуманитарного образования СамГТУ;

- рекомендовано к изданию.

В 2016/2017 учебном году запланировано внедрение учебно-методического пособия в процесс обучения бакалавров 3 курса, обучающихся по направлению 42.03.01 Реклама и связи с общественностью, профиль «Связи с общественностью».

Внедрение пособия в процесс обучения бакалавров 3 курса, обучающихся по направлению 42.03.01 Реклама и связи с общественностью позволит повысить уровень подготовки студентов за счет аккумуляции знаний, умений, владений из разных дисциплин для решения профессиональной задачи.

\section{СПИСОК ЛИТЕРАТУРЫ:}

1. Фролко М.С. Рекомендации преподавателям по созданию учебно-методических материалов. М.: ФГБОУ ВПО «РГУФКСМиТ», 2013. 35 с.

2. Тимощук Н.А. Преемственность в реализации федеральных государственных образовательных стандартов // Математическое образование: прошлое, настоящее и будущее: Мат-лы IV Всерос. III Междунар. заочной науч.-практ. конф., посвящ. 100-летию со дня рожд. К.А. Малыгина. Самара: ПГСГА, 2015. С. 268274.

3. Плеханова Т.М. Синергетика метапредметных компетенций (на примере подготовки бакалавров по связям с общественностью) // Синергетика природных, технических и социально-экономических систем: XIII Междунар. науч. конф. Тольятти: Изд-во ПВГУС, 2015. С. 180-185.

4. Тимощук Н.А. Формирование метапредметной компетентности у студентов технического университета // Вестник Самарского государственного технического университета. Серия «Психолого-педагогические науки». 2015. № 3(27). С. 233-241.

5. Плеханова Т.М., Мельник Н.М. Подготовка эффективного специалиста по социальной рекламе в условиях становления инновационного общества // Связи с общественностью в пространстве межкультурной коммуникации: императивы модернизации и управление изменениями: Междунар. науч.-практ. конф. Самара: СамГТУ, 2012. С. 133-137.

6. Плеханова Т.М. Реальное практико-ориентированное учебное проектирование как фактор развития и формирования у студентов профессиональной ком- петентности // Вестник Самарского государственного технического университета. Серия: Психолого-педагогические науки. 2015. № 2 (26). С. 138-145.

7. Плеханова Т.М. Синергетика метапредметных компетенций (на примере подготовки бакалавров по связям с общественностью) // Синергетика природных, технических и социально-экономических систем. XIII Междунар. науч. конф. Тольятти: Изд-во ПВГУС, 2015. С. 180-185.

8. Насанова Б.Б. Междисциплинарные связи в системе СПО: компетентностный подход // Среднее профессиональное образование. 2013. № 12. С. 7-9.

9. Ульянова О.В. Междисциплинарность как основополагающий принцип формирования профессиональной компетентности студентов технических вузов // Профессиональное образование в России и за рубежом. 2012. № 8. С. 65-68.

10. Лаптева М.П. Междисциплинарность как методологический феномен // Вестник Пермского университета. Серия «История». 2011. № 1(15). С. 165-167.

11. Бушковская Е.А. Феномен междисциплинарности в зарубежных исследованиях // Вестник Томского государственного университета. 2010. № 330. С. $152-155$.

12. Соловьев А.А. Образование: междисциплинарность и разделенность // Известия Волгоградского государственного технического университета. 2013. № 16(119). С. 27-30.

13. Платонова С.И. Междисциплинарность в современном социальном знании // Теория и практика общественного развития. 2012. № 12. С. 41-44.

14. Бушковская Е.А. Междисциплинарное обучение как способ формирования коммуникативной компетентности (на примере уроков английского языка) // Молодой учёный. 2014. № 5 (64). С. 492-495.

15. Снопкова Е.И. Актуальность междисциплинарного подхода в педагогических исследованиях: научное обоснование // Интеграция образования. 2015. Т. 19, № 1. С. 111-117.

16. Правила подготовки рукописи к изданию: метод. указания / сост. Е.С. Захарова. Самара: Самар. гос. техн. ун-т, 2009. 44 с.

17. Методические указания по разработке учебного пособия [Электронный ресурс] // Сайт Якутского колледжа технологии и дизайна. - http://www.yctd.ru/ ?q=content/методические-указания-по-разработкеучебного-пособия.

18. Михеева Е.Н., Перова Л.А. Разработка учебнометодического пособия как показатель компетентности педагога // Научные исследования в образовании. 2011. № 10. С. 67-70.

19. Рябинова Е.Н., Марченкова Л.А. К вопросу об актуальности формирования вербальных компетенций студентов технических вузов // Вестник Самарского государственного технического университета. Серия «Психолого-педагогические науки». 2015. № 2(26). С. 163-170.

20. Рябинова Е.Н., Марченкова Л.А. Формирование вербальных компетенций в процессе профессиональной подготовки будущих инженеров // Вектор науки ТГУ. Серия: педагогика, психология. 2015. № 4(23). С. 158-163. 


\title{
TRAINING HANDBOOK AS MEANS OF ORGANIZATION OF INTERDISCIPLINARY CONNECTIONS IN THE PROCESS OF BACHELORS TRAINING
} (C) 2016

\author{
T.M. Plekhanova, senior lecturer of the Chair of Psychology and Pedagogics \\ Samara State Technical University, Samara (Russia)
}

\begin{abstract}
This paper discusses the theoretical aspects and relevance of the interdisciplinary approach in the pedagogical process. An interdisciplinary teaching aid for public relations, developed at Psychology and Pedagogy Department of SSTU, is considered to be a form of interdisciplinary connections formation in the process of bachelors training whose major is 42.03 .01 «Advertising and public relations». This study guide is a part of the educational complex for the courses «Theory and Practice of Public Relations», «Theory and Practice of the media», «Fundamentals of communication theory» and is supposed to be used as part of their practical training. Interdisciplinary potential of this training manual is that the content and didactic units of different disciplines complement each other, forming a single integral perception of the subject. In terms of developing competencies students acquire a wide range of knowledge and skills as well as perceive a continuity and consistency between the results of the planned development of the disciplines. Implementation benefits Bachelors' 3rd year learning process and lets the students majoring in «Advertising and public relations» improve the level of training due to the accumulation of knowledge and skills from different disciplines to solve professional problems.

Keywords: interdisciplinarity; interdisciplinary studies; teaching aid; pedagogical process; bachelor; students; discipline; competence; ownership; skills; Samara State Technical University; advertising; public relations; communication.
\end{abstract}

УдК 37.015.3:177

\section{ПЕДАГОГИЧЕСКИЕ АСПЕКТЫ ДУХОВНО-ПРАКТИЧЕСКОГО ОСВОЕНИЯ ДЕЙСТВИТЕЛЬНОСТИ В МОРАЛИ} (C) 2016

О.К. Позднякова, доктор педагогических наук, профессор, член-корреспондент Российской академии образования, профессор кафедры педагогики и психологии Самарский государственный соииально-педагогический университет, Самара (Россия)

Аннотация. В статье обосновывается необходимость осмысления морали, как способа духовно-практического освоения человеком действительности, в контексте педагогического знания. Аргументируется, что духовно-практическое освоения действительности осуществляется при участии морального сознания, в механизмах функционирования которого заложены способы ориентации человека в социальном мире, в мире ценностей. Выявляется взаимосвязь морали и нравственного сознания. Мораль проявляется в поведении и поступках, в деятельности и действиях, в отношениях человека. Нравственное сознание, состоящее из представлений, взглядов, оценок, позволяет совершать выбор поступков и действий, которые реализуются в поведении и в деятельности. Представлены основания различения морали и нравственности: мораль объемлет объективное, а нравственность есть субъективное. Обосновывается, что нравственное сознание учителя, участвующее в духовно-практическом освоении действительности в морали, есть такое идеальное, которое определенным образом организует и регулирует его действия по воспитанию и обучению детей. Установлено, что духовнопрактическое освоение действительности в морали происходит на основе нравственного сознания, в котором деонтологическое и аксиологическое, оценочное и мотивационное находятся в единстве и взаимосвязи. Учитель, реализуя аксиологическое и деонтологическое через приобщение учащихся к ценностям, достигая цели образования, развивает двойную мотивацию учащихся, суть которой заключается в единстве деонтологического и аксиологического аспектов духовно-практического освоения действительности в морали.

Ключевые слова: учитель; ученик; мораль; духовно-практическое освоение действительности; моральное сознание; нравственное сознание; нравственность; ценность; педагогическая рефлексия; педагогическая деятельность; поступки; поведение; оценка; мотивация; отношения; выбор.

Содержание образования и его цели определяются как социальным, так и общекультурным контекстом жизни общества. Тот факт, что сегодня российское общество переориентируется на ценности, прежде всего нравственные, определяющие выбор человеком отдельных поступков и линии поведения в целом, показывает, что в образовании происходит переход от единообразия к многообразию. Многообразие, в отличие от единообразия, диктующего педагогу четкую последовательность этапов педагогической деятельности, и жестко задающего ее результаты, дает учителю возможность свободно, без внешней диктовки выбирать формы и методы обучения и воспитания учащихся на всех ступенях образования. Переход к многообразию от единообразия позволяет осуществить замену ролевого способа педагогической деятельности культурным способом, который наиболее отвечает ее природе.

В тоже время образование, получив свободу выбора, зачастую направляет свои ресурсы не на формирование человека нравственного, а на формирование человека успешного, который в первую очередь ориентирован не на благо, а на пользу. В образовании, приобретающем черты сферы услуг, явно про- 